\title{
Desarrollo de un proceso para el aprovechamiento integral de la toronja
}

\author{
Esbán Isaí Escobedo Álvarez ${ }^{1}$
}

\section{Resumen}

Este proyecto posee un enfoque sustentable encaminado al desarrollo de una línea de procesos que permitan darle un valor agregado a la toronja; implantando una empresa sustentable que permita generar el mínimo de desechos.

Se basa en un proceso principal donde se extrae el jugo y se envasa sin conservadores siendo pasteurizado para mantener sus propiedades intactas, es decir, los bioflavonoides de la toronja permiten que el cuerpo humano aproveche al máximo las medicinas consumidas y disminuir las dosis ingeridas por personas enfermas. Además de que lo puede consumir cualquier persona.

La pectina y el extracto antibacterial serán elaborados de los desechos producidos del proceso principal; la primera será dirigida para las industrias alimenticias y la segunda para diversas industrias, en la elaboración de detergentes, jabones y geles antibacteriales.

Con el mínimo de desechos, cuidamos el medio ambiente y formaremos parte de la nueva era de empresas sustentables.

Palabras Clave: proceso, aprovechamiento, integral, toronja 


\section{Abstract}

Nowadays and considering the diverse and highly competitive market, companies are required store and analyse a wide variety of information. Expert Systems stand out from the support tools of decision-making. They are designed to facilitate tasks in many application fields and provide results equivalent to a specialist, emulating the human capacity to make decisions according to context conditions.

This paper is a compendium which introduces the origin of Expert Systems, its main features, its link to artificial intelligence, the different associated technologies and its application to science and industry. In addition, it briefly describes the technologies and frameworks available today to design and implement an Expert System in different areas or markets. Finally, the work is completed with a brief analysis describing the advantages, limitations and current trends in Expert Systems.

Keywords: process, comprehensive utilization, grapefruit. 


\section{Introducción}

La toronja o pomelo (Citrus x paradisi) es un árbol de la familia de las rutáceas, cultivado por su fruta. Es un híbrido, probablemente producido de forma espontánea entre la pampelmusa (Citrus máxima) y la naranja dulce (Citrus x sinensis). El estado de Michoacán ocupa el segundo lugar de producción a nivel nacional de toronja según datos de la SAGARPA como se muestra a continuación en la tabla 1.

\begin{tabular}{|c|c|c|c|c|c|c|}
\hline & & $\begin{array}{l}\text { PRODU } \\
\text { Ciclo: Cic } \\
\text { Moc }\end{array}$ & $\begin{array}{l}\text { CCION AGR } \\
\text { clicos y Perenn } \\
\text { dalidad Riego+ Tempor } \\
\text { TORONA (POMELIO) }\end{array}$ & $\begin{array}{l}\text { ICOLA } \\
\text { es } 2012\end{array}$ & & \\
\hline Ubicación & $\begin{array}{l}\text { Sup. } \\
\text { Sembrada } \\
\text { (Ha) }\end{array}$ & $\begin{array}{l}\text { Sup. } \\
\text { Cosechada } \\
\text { (Ha) }\end{array}$ & $\begin{array}{l}\text { Producción } \\
\text { (Ton) }\end{array}$ & $\begin{array}{l}\text { Rendimiento } \\
\text { (Ton/Ha) }\end{array}$ & $\begin{array}{l}\text { PMR } \\
\text { (\$/Ton) }\end{array}$ & $\begin{array}{c}\text { Valor } \\
\text { Producción } \\
\text { (Miles de } \\
\text { Pesos) }\end{array}$ \\
\hline $\begin{array}{l}\text { BAJA } \\
\text { CALIFORNIA }\end{array}$ & 13.90 & 12.00 & 127.80 & 10.65 & $3,222.22$ & 411.80 \\
\hline $\begin{array}{l}\text { BAJA } \\
\text { CALIFORNIA } \\
\text { SUR }\end{array}$ & 23.00 & 23.00 & 273.00 & 11.87 & $5,434.07$ & $1,483.50$ \\
\hline CAMPECHE & 681.50 & 541.50 & $13,513.50$ & 24.96 & $3,598.45$ & $48,627.64$ \\
\hline COLIMA & 15.00 & 15.00 & 180.00 & 12.00 & $4,608.11$ & 829.46 \\
\hline DURANGO & 182.00 & 182.00 & 568.30 & 3.12 & $4,078.14$ & $2,317.61$ \\
\hline GUERRERO & 5.00 & 5.00 & 64.40 & 12.88 & $3,541.62$ & 228.08 \\
\hline JALISCO & 136.59 & 136.59 & $1,290.81$ & 9.45 & $4,443.15$ & $5,735.26$ \\
\hline MICHOACAN & $4,080.80$ & $3,729.30$ & $40,500.45$ & 10.86 & $2,387.43$ & $96,692.18$ \\
\hline MORELOS & 6.00 & 6.00 & 181.80 & 30.30 & $3,624.69$ & 658.97 \\
\hline $\begin{array}{l}\text { NUEVO } \\
\text { LEON }\end{array}$ & $1,762.50$ & $1,762.50$ & $26,425.50$ & 14.99 & $1,097.09$ & $28,991.28$ \\
\hline OAXACA & 190.00 & 190.00 & $2,285.40$ & 12.03 & 775.73 & $1,772.86$ \\
\hline PUEBLA & 384.00 & 384.00 & $4,208.00$ & 10.96 & $1,006.78$ & $4,236.52$ \\
\hline $\begin{array}{l}\text { SAN LUIS } \\
\text { POTOSI }\end{array}$ & 7.00 & 7.00 & 47.25 & 6.75 & $1,150.00$ & 54.34 \\
\hline SINALOA & 236.00 & 39.00 & 294.00 & 7.54 & $1,863.47$ & 547.86 \\
\hline SONORA & 806.00 & 650.00 & $20,221.00$ & 31.11 & $1,759.29$ & $35,574.60$ \\
\hline TABASCO & 110.00 & 110.00 & 875.00 & 7.96 & $1,149.71$ & $1,006.00$ \\
\hline TAMAULIPAS & $1,771.20$ & $1,705.00$ & $35,542.30$ & 20.85 & $2,748.00$ & $97,670.19$ \\
\hline VERACRUZ & $7,370.75$ & $7,155.75$ & $261,548.60$ & 36.55 & $1,418.64$ & $371,042.83$ \\
\hline \multirow[t]{2}{*}{ YUCATAN } & 442.36 & 428.57 & $7,323.74$ & 17.09 & $2,688.71$ & $19,691.44$ \\
\hline & $18,223.60$ & $17,082.21$ & $415,470.85$ & 24.32 & $1,727.13$ & $717,572.40$ \\
\hline
\end{tabular}

Tabla 1: Producción nacional de toronja al 2012 
En la tabla 2 se muestra la producción actualizada del último mes (se omitieron de la tabla las celdas de los estados con menor producción)

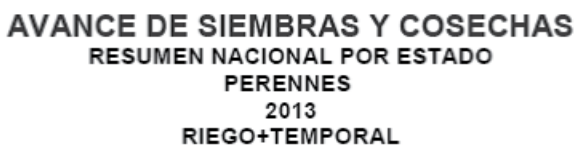

Datos Preliminares

TORONJA (POMELO)

\begin{tabular}{|c|c|c|c|c|c|}
\hline \multirow{2}{*}{ Estado } & \multicolumn{3}{|c|}{ Superficie (ha) } & \multirow{2}{*}{$\frac{\begin{array}{c}\text { Producción } \\
\text { (ton) }\end{array}}{\text { obtenida }}$} & \multirow{2}{*}{$\begin{array}{c}\begin{array}{c}\text { Rendimiento } \\
\text { (ton/ha) }\end{array} \\
\text { obtenido }\end{array}$} \\
\hline & sembrada & cosechada & siniestrada & & \\
\hline CAMPECHE & 682 & 540 & 40 & 13,500 & 25.000 \\
\hline MICHOACAN & 4,082 & 3,696 & & 14,601 & 3.950 \\
\hline NUEVO LEON & 1,892 & 942 & & 18,114 & 19.229 \\
\hline TAMAULIPAS & 2,152 & 637 & & 15,332 & 24.071 \\
\hline VERACRUZ & 7,418 & 2,552 & & 79,078 & 30.987 \\
\hline TOTAL & 18,271 & 9,281 & 40 & 160,658 & 17.310 \\
\hline
\end{tabular}

Fuente: Elaborado por el Servicio de Información Agroalimentaria y Pesquera (SIAP), con información de las Delegaciones de la SAGARPA.

Tabla 2: Avance de siembras y cosechas, resumen por estado.

La toronja es un importante producto agrícola en el municipio de Apatzingán. Sin embargo, no tiene ningún valor agregado, dado que se produce sólo para exportación o consumo local como fruta fresca, o sea que no se le transforma de ningún modo.

Además, dado que sólo se consume la pulpa del fruto, se tiene el problema del desperdicio de cáscara y semilla. En algunos lugares se ha visto que dada la baja demanda, los productores prefieren no cosechar el fruto, por lo que las toronjas caen y se descomponen en el suelo, provocando a futuro la acidificación del mismo.

Es por ello que se ha decidido diseñar un proceso de fabricación que no sólo le agregue valor a este producto citrícola, sino que además aproveche todas las partes del fruto, para que los desperdicios sean prácticamente nulos, disminuyendo asimismo la contaminación ambiental.

Es necesario el aprovechamiento de la toronja en la región de Apatzingán, debido a que en la actualidad gran parte de esta materia prima es desperdiciada trayendo como consecuencias grandes pérdidas económicas para el sector agrícola.

Es por ello que se propone una línea de procesos la cual nos ayude al aprovechamiento óptimo de ésta, obteniendo el menor desperdicio posible. 


\section{Propuesta}

La línea de proceso que se propone tiene como producto principal la obtención de jugo de toronja a partir de la pulpa obteniendo un jugo de buena calidad y con características optimas que nos permitan hacerlo de una manera natural para su comercialización.

Esté jugo se obtendrá mediante la pasteurización y el filtrado del jugo obtenido de la pulpa de toronja, posteriormente será envasado.

Al aplicar el proceso antes mencionado a la toronja, contaremos con dos residuos sumamente importantes como lo son la cascara y la semilla; es de aquí donde obtendremos nuestros subproductos.

Por una parte se realizara un proceso de extracción de pectina a la cascara, el cuál será lanzado al mercado para industrias alimentarias y en algunos casos para las industrias farmacéuticas. En las industrias alimentarias se utiliza como una especie de aditivo a los alimentos para darle características espesantes, emulsificantes y estabilizantes; en mermeladas, gelatinas de frutas y en las industrias farmacéuticas se utiliza debido a sus enlaces que puede llegar a formar para inhibir proteínas que facilitarían la diseminación del cáncer en el organismo

Otro subproducto importante es el que resulta del proceso de extracción de la semilla el cuál es un agente eficaz para combatir virus y bacterias además de un gran número de parásitos unicelulares.

Mediante la realización de estas tres técnicas que conforman una línea de proceso que serán implantadas en una empresa de la región, se logran resultados favorables para la economía de la región, aprovechando la materia prima que antes era desperdiciada, generando una línea de productos novedosos así como la generación de nuevos empleos.

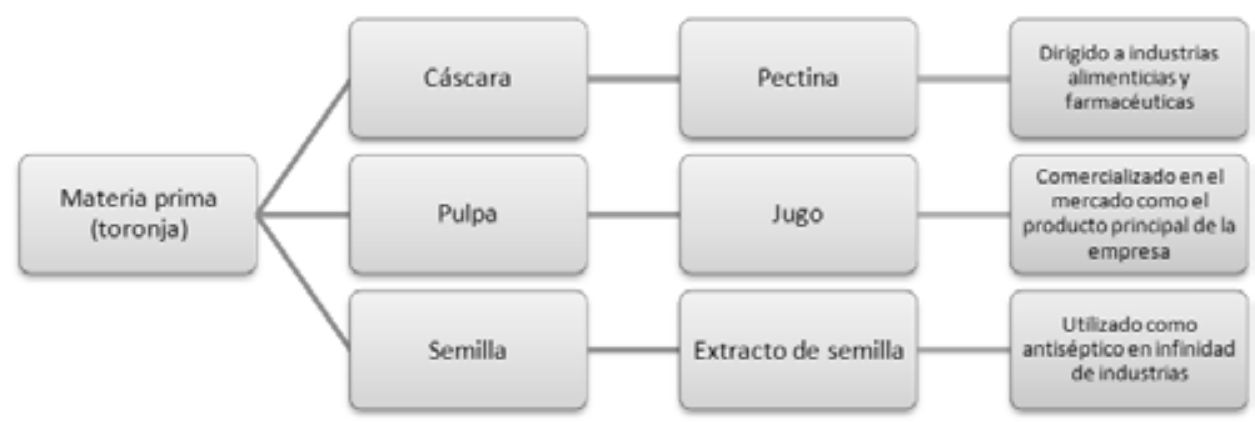

Figura 1: Proceso de aprovechamiento integral de la toronja. 


\section{Objetivos}

- Diseñar una línea de procesos para el aprovechamiento integral de la toronja que permita una producción sustentable con el mínimo de desechos y asegurando su calidad.

- El aprovechamiento de materia prima (toronja) desperdiciada, mediante el uso de procesos que transformen la toronja en un producto principal y dos subproductos.

- Implantación de una empresa agroindustrial sustentable.

- Reducción de daño ecológico producido por el desecho de empresas.

\section{Materiales y métodos}

Para llevar a cabo la elaboración de nuestro producto, se buscaron los procesos más adecuados para el máximo aprovechamiento de la materia prima.

Es por ello que se decidió utilizar el siguiente proceso en la fabricación del producto principal; asimismo se analizaron otros procesos con el fin de aprovechar los desechos resultantes llegando a la conclusión de incluir una línea de procesos en donde se obtuviera pectina de la cáscara y de la semilla un extracto antiséptico.

Jugo de toronja

Para llevar a cabo la producción de un jugo de toronja con calidad, se realiza una pasteurización por medio de choque de calor, en el cual a la toronja se le elimina la cáscara, quedando sólo la pulpa. Esta pulpa es exprimida para la obtención del jugo. Posteriormente el jugo es envasado en botellas de vidrio previamente esterilizadas, se somete a una pasteurización de $65^{\circ} \mathrm{C}$ por un periodo de $30 \mathrm{~min}$. Una vez cumplido este tiempo se sacan las botellas y se someten a un choque de temperatura de $20^{\circ} \mathrm{C}$ durante 30 segundos, pasando después a otro choque de temperatura de $5^{\circ} \mathrm{C}$ durante 10 minutos. Finalmente el jugo es almacenado en cámaras frigoríficas con una temperatura de $15^{\circ} \mathrm{C}$.

Se realiza este proceso debido a que se busca la creación de un jugo 100\% natural, sin conservadores, para así conservar las propiedades de la toronja.

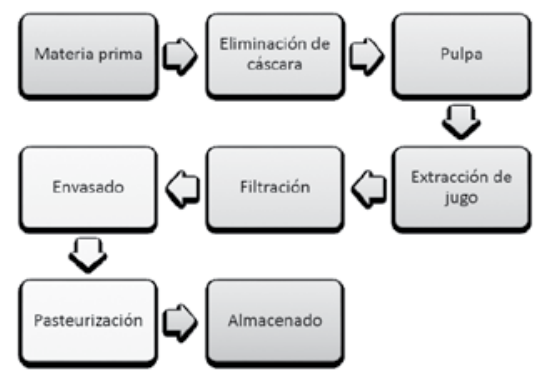

Figura 2: Elaboración de jugo. 


\section{Extracto de semilla de toronja}

Para llevar a cabo el proceso de extracción de la semilla de toronja, la semilla que es desechada en la filtración del jugo se deshidrata, después la semilla es triturada con ayuda de un molino, posteriormente este extracto es envasado y almacenado en un lugar fresco para que no exista contaminación del mismo.

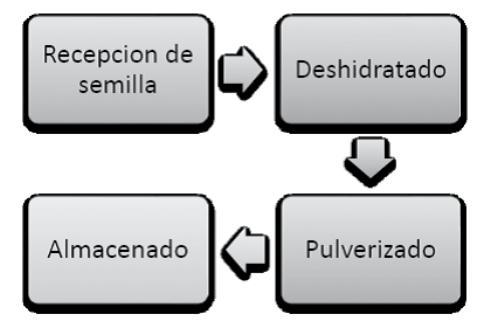

Figura 3: Extracto de semilla.

\section{Pectina}

Para la obtención de la pectina, que se encuentra en la cáscara de la toronja, se realiza el siguiente proceso:

- Recepción de materia prima: Se recibe la cáscara que fue desechada de la obtención del jugo de la toronja.

- Selección de la cáscara: Es seleccionada la cáscara que se encuentre en óptimas condiciones separándola de la que se encuentra en mal estado o contenga hongos, que puedan alterar la calidad de la pectina.

- Inactivación enzimática: Con el propósito de hacer más eficiente el proceso de extracción es necesario inactivar las enzimas pécticas, poniendo la cascara en agua, con concentraciones cercanas a 300 gramos por litro y calentando hasta ebullición, esto con la finalidad de eliminar suciedades o microrganismos presentes en la cáscara. La solución se filtra y la cáscara queda lista para la hidrólisis.

- Hidrolisis ácida: A la cáscara se le agrega la misma cantidad de agua usada inicialmente (300 gr de cáscara por litro de agua), y a la solución se le agrega ácido clorhídrico hasta obtener un $\mathrm{pH}$ entre 1.5 y 3 . Si se usa ácido clorhídrico al $37 \%$ se utiliza de 6 a $7 \mathrm{ml}$ por litro de agua, posteriormente se lleva a cabo un calentamiento de 30 a 40 minutos a partir del momento que se alcanza el punto de ebullición; debe mantenerse una agitación constante para evitar que la cáscara se deposite en el fondo de la hidrólisis.

- Filtración de los residuos: Una vez que se suspende la agitación se filtra la solución para separar el material solido del material líquido.

- Concentración: Para preparar la solución para la precipitación es necesario 
concentrarla, esta concentración tiene por objeto disminuir el uso del alcohol en el proceso de precipitación.

- Precipitación: Para la precipitación de la pectina se utiliza etanol, se recomienda un volumen del $60 \%$ de la solución que se va a precipitar.

- Lavado: El aspecto final de la pectina depende del proceso de lavado, que se debe realizar varias veces, considerando el grado de impurezas que pueda contener y modificar su color. Este proceso consiste en diluir la pectina, que está separada en el filtro, en agua acidulada ( $\mathrm{pH}$ ente 1.5 y 3 ), y precipitarla nuevamente con alcohol.

- Secado: El proceso de secado se realiza a baja temperatura (menor a $40^{\circ} \mathrm{C}$ ) en una corriente de aire caliente, por unas doce horas.

- Molienda: Para homogeneizar el tamaño de la partícula y mejorar la apariencia de la pectina se muele en un molino, de un tamaño de 1 pulgada aproximadamente, hasta que pase por un tamiz.

- Almacenamiento: La pectina debe almacenarse en un lugar seco y en recipientes que la protejan de la humedad, para evitar la contaminación y modificaciones en su apariencia y en su calidad.

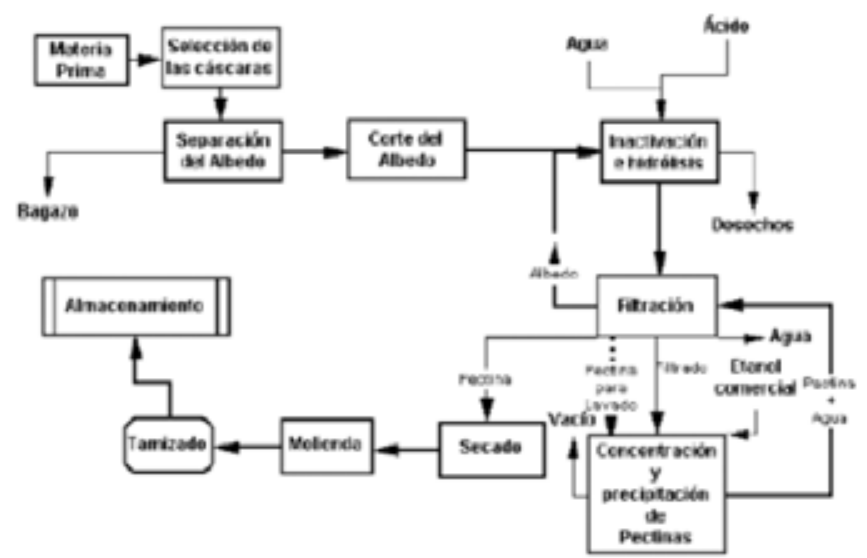

Figura 4: Obtención de pectina

\section{Resultados esperados}

El proyecto contribuye con los siguientes beneficios en el municipio de Apatzingán:

- Creación de micro, pequeña y mediana empresa.

- Generación de empleos, tanto directos como indirectos:

o Directos: Accionistas, Obreros, profesionistas, etc.

o Indirectos: Productores agrícolas, jornaleros, proveedores de insumos y servicios, etc.

- Se le da un valor agregado para la obtención de mayores utilidades en la producción de la toronja, porque su valor en el mercado como fruta fresca es bajo. 
- Mayor inversión empresarial nacional o extranjera.

- Incremento en el sector agrícola, ya que las tierras y condiciones climáticas del Valle de Apatzingán son favorables para el cultivo de la toronja.

- Induce la integración de organizaciones económicas para la producción y comercialización. Ejemplo: Sociedades de producción rural y sociedades anónimas.

- Promoción de desarrollo regional (generación de riquezas).

- Disminuye los niveles de pobreza de la población.

- Disminuye el nivel de criminalidad.

- Contribución a la disminución de enfermedades relacionadas con la gripe (contiene vitamina $\mathrm{C}$ ), control de peso (dietético), cáncer, etc.

Haciendo estimaciones acerca de la oferta que existe de toronja actualmente en el mercado local, así como de la potencial demanda de los productos, se hace una estimación de una provisión diaria de 10 toneladas de toronja.

Además, se calcula que con esta cantidad de toronja, diariamente se producirán 4000 litros de jugo. Otra estimación indica que con los residuos restantes de la elaboración del jugo se pueden fabricar $100 \mathrm{~kg}$ de pectina y $20 \mathrm{~kg}$ de extracto de la semilla de toronja.

\section{Impacto ambiental}

La implantación de la empresa lograra un impacto favorable al medio ambiente debido a los procesos con los que se trabaja.

El desperdicio de la toronja en los campos que ésta es sembrada trae como consecuencia la acidificación del suelo; esto es debido al bajo $\mathrm{pH}$ que posee la toronja, ya que al descomponerse y hacer contacto con el suelo reacciona provocando una disminución del $\mathrm{pH}$ de la tierra, causando una infertilidad en estás; es por ello que la implantación de esta empresa disminuirá este problema de contaminación en los suelos de la región de Tierra Caliente Michoacana, contando con suelos más fértiles y menos contaminados.

Los procesos con los que trabajará la empresa están basados en el aprovechamiento máximo de los recursos de la materia prima, disminuyendo los residuos; gracias a esto se evitará la contaminación de las aguas, suelos y aire; obteniendo una empresa sustentable dentro de la región. Uno de los puntos importantes que busca obtener la empresa es motivar a todas las empresas dentro del área, que generen procesos que aporten en lo más mínimo desechos tóxicos y contaminantes hacia el ambiente.

Se tiene previsto también el tratamiento de aguas residuales para esta línea de procesos, puesto que se aprovechará en su mayoría la toronja, no se generan residuos peligrosos ni contaminantes de la materia prima, solamente habrá que tratar el agua que se estará utilizando. 


\section{Conclusiones}

Actualmente en el mercado no existen suficientes empresas que se dediquen al aprovechamiento máximo de la toronja y menos en la región de Tierra Caliente de Michoacán. En algunas empresas donde se procesan cítricos en la región, se generan residuos que pueden llegar a ser dañinos tanto para el medio ambiente como para la sociedad y sólo se dedican a una sola línea de producción (extracción de jugo o aceite). Es por ello que se necesita la creación de una empresa que dé un giro distinto a lo que se ha venido realizando hasta el día de hoy. Estudios elaborados recientemente han demostrado que la toronja contiene un sinfín de propiedades que son benéficas para el ser humano, el jugo de toronja ayuda a absorber con más facilidad medicamentos tomando una dosis más baja, el extracto de semilla es un poderoso antiséptico que elimina bacterias como la E Coli y la salmonella. La pectina se utiliza en una infinidad de industrias, alimenticias y farmacéuticas entre otras; es por ello que aplicando estas propiedades se decide, a diferencia de otras empresas, realizar una línea de procesos que como objetivos principales contribuyan al bienestar del consumidor y a la regeneración del medio ambiente, evitando en lo posible la contaminación por la fabricación de los productos. 


\section{Bibliografía}

Casa Pia, todo lo relacionado con temas de salud natural (2013) El Pomelo: Propiedades nutritivas y principios activos. Disponible en:

http://www.casapia.com/Paginacast/Paginas/Paginasdemenus/MenudeInformaciones/ ComplementosNutricionales/Extracto-Semilla-Pomelo.htm(2013, 6 de mayo)

Comisión veracruzana de comercialización agropecuaria (2010) Monografía de la toronja. Gobierno del estado de Veracruz. Disponible en:

http://portal.veracruz.gob.mx/pls/portal/docs/PAGE/COVECAINICIO/ IMAGENES/ARCHIVOSPDF/ARCHIVOSDIFUSION/MONOGRAFIA $\% 20$ TORONJA2010.PDF (2013, 19 de febrero)

Formoso, A. (1992). 2000 Procedimientos industriales al alcance de todos (13a ed.). México, D.F.: Editorial Limusa.

Servicio de información agroalimentaria y pesquera (2013, 30 de Junio) Resumen nacional de la producción agrícola. Secretaría de agricultura, ganadería, desarrollo rural, pesca y alimentación (SAGARPA). Disponible en:

h t t p : / / w w w s i a p.gob.mx/index.php? o p tion=com wrapper\&view $=$ wrapper\&Itemid $=300(2013,2$ de julio $)$

Servicio de información agroalimentaria y pesquera (2013, 30 de Junio) Cierre de la producción agrícola por cultivo. Secretaría de agricultura, ganadería, desarrollo rural, pesca y alimentación (SAGARPA). Disponible en:

h t t p :// w w w . s i a p.gob.m x/index.php? op tion=com wrapper\&view=wrapper\&Itemid=301 (2013, 2 de julio) 
